\title{
Diaporthe nobilis, a new record on Camellia sinensis in Guizhou Province, China
}

\section{Li $Y^{1,2}$, Tan $\mathbf{P}^{3}$ and Zhao DG ${ }^{1,2^{*}}$}

${ }^{1}$ The Key Laboratory of Plant Resources Conservation and Germplasm Innovation in Mountainous Region, (Ministry of Education), Institute of Agro-Bioengineering and College of Life Sciences, Guizhou University, Guiyang, 550025, Guizhou, China

${ }^{2}$ The State Key Laboratory Breeding Base of Green Pesticide and Agricultural Bioengineering Guizhou University, Guiyang, 550025, Guizhou, China

${ }^{3}$ Agricultural experiment center of Guiyang City, Wudang District, 550007, Guizhou, China

Li Y, Tan P, Zhao DG 2017 - Diaporthe nobilis, a new record on Camellia sinensis in Guizhou Province, China. Mycosphere 8(1), 1-8, Doi 10.5943/mycosphere/8/1/1

\begin{abstract}
One Diaporthe strain was isolated from diseased leaves of Camellia sinensis in Guizhou Province. It is characterized by the production of two types conidia ( $\alpha, \beta$-conidia). Morphologically the species is very similar to Phomopsis laurella (syn. Diaporthe nobilis) in producing cylindrical or ellipsoidal $\alpha$-conidia with two oil drops. Phylogenetic analysis of combined ITS, $\beta$-tubulin and tefl sequence data shows that these strains are placed in $D$. eres species complex. Critical examination of the phenotypic characters indicated that this strain represents Diaporthe nobilis, a new record in Camellia sinensis.
\end{abstract}

Key words - coelomycetes - phylogeny - taxonomy - tea

\section{Introduction}

Tea (Camellia sinensis) is most popular beverages in the world. More than three million hectares of the world's arable land is covered by tea plantations ( $\mathrm{Li}$ et al. 2011). In Guizhou Province, the area of tea plantations has achieved 0.29 million ha in 2011 , which centralizes in Zunyi and Qiannan cities. During 2011-2012, we investigated the fungal diversity of $C$. sinensis in Guizhou provinces, Colletotrichum spp., Phoma spp., Alternaria spp., Diaporthe spp., Pestalotiopsis spp. and Exobasidium spp. were discovered in the leaves of $C$. sinensis. Among them, they also include important or new tea pathogens.

Diaporthe Nitschke is the sexual state of Phomopsis with more than 800 names included in Index fungorum mostly independent of any anamorphic affinities (Udayanga et al. 2011). A single name must now be applied for the different morphs of Phomopsis / Diaporthe (Shenoy et al. 2007, Hawksworth 2011, Hyde et al. 2011, 2014). Santos \& Phillips (2009) proposed to give preference 
to the older Diaporthe (1870) names, rather than the younger anamorphic genus, Phomopsis (1905) and this has been followed by subsequent authors (Udayanga et al. 2011, 2012, 2014, Liu et al. 2015, Hyde et al. 2016). The coelomycetes strain only producing anamorph was discovered from $C$. sinensis leaves in Guizhou province, whose morphological characters of conidia and conidiophores are very similar to D. fukushii. For phylogeny, Udayanga et al. (2011) proposed "the rDNA ITS phylogenetic tree generated here is based on the phylogenetic backbone tree as a rough and quick identification guide for fresh isolates of Diaporthe species". Meanwhile, the combined analysis of more than one gene provides higher resolution than a single gene (Udayanga et al. 2012).

Diaporthe eres Nitschke is the type species of Diaporthe, which was described by Nitschke (1870). Wehmeyer (1933) listed a number of synonyms under this species with approximately 70 plant host associations based on only morphological observations. Following individual and combined analyses of multi-gene DNA sequences, Udayanga et al. (2014) accept only nine Diaporthe species belonging to $D$. eres species complex and epitypified six species, which provide powerful convenience to identify species in this complex. Fortunately, Gao et al. (2016) investigated Diaporthe species with Camellia in China, and in this paper four novel species and three known species were reported by morphological comparison and multi-gene analyses, which provided abundant reference information for our study. This paper based on morphological observation and three gene regions (ITS, $\beta$-tubulin and tefl) analysis indicated our coelomycetous strain differed to other Diaporthe species in D. eres species complex, but very close to Diaporthe nobilis. Finally, we determined our strain should be D. nobillis, which is also the first record on Camellia sinensis in China.

\section{Materials \& Methods}

\section{Isolation and morphological studies}

Infected tea leaves were collected from Huishui, Guizhou Province. Single-spore isolation was used to obtained pure culture of pathogens (Choi et al. 1999). For the growth study the culture was grown on Potato Dextrose Agar (PDA), Corn Meal Agar (CMA) and Czapek Solution Agar $(\mathrm{CZ})$ at $25^{\circ} \mathrm{C}$ for $8 \mathrm{~d}$. Plates were inoculated with $5 \mathrm{~mm}$ plugs taken from an actively growing colony on CM. The plugs were placed at the edge of a $90 \mathrm{~cm}$ petri dish. A colony diameter of $7 \mathrm{~cm}$ indicates that the colony has reached the edge of the petri dish. Cultural characteristics and morphology were determined on tea leaf agar (TLA) [1\% water agar $(10 \mathrm{~g} / \mathrm{L})$ with autoclaved carnation leaves placed onto the medium] and incubated for 7 days at $25^{\circ} \mathrm{C}$ under continuous near-UV light, to promote sporulation. A water solution of $60 \%(\mathrm{v} / \mathrm{v})$ lactic acid without a color dye was used as the mounting medium. Slides were examined under oil immersion with a Nikon 80i microscope (Nikon Corporation, Japan) at 1000× magnification. The specimens and living culture were deposited in the Herbarium of the Department of Plant Pathology, Agricultural College, Guizhou University (HGUP).

\section{DNA extraction, PCR and sequencing}

Total genomic DNA was extracted from the pure culture using modified CTAB protocol described in Guo et al. (2000). Primer pairs ITS1/ITS4 (White et al. 1990), Bt2a/Bt2b (Glass \& Donaldson 1995), and EF1-728F/EF1-986R (Carbone et al. 1999) were used to amplify partial 


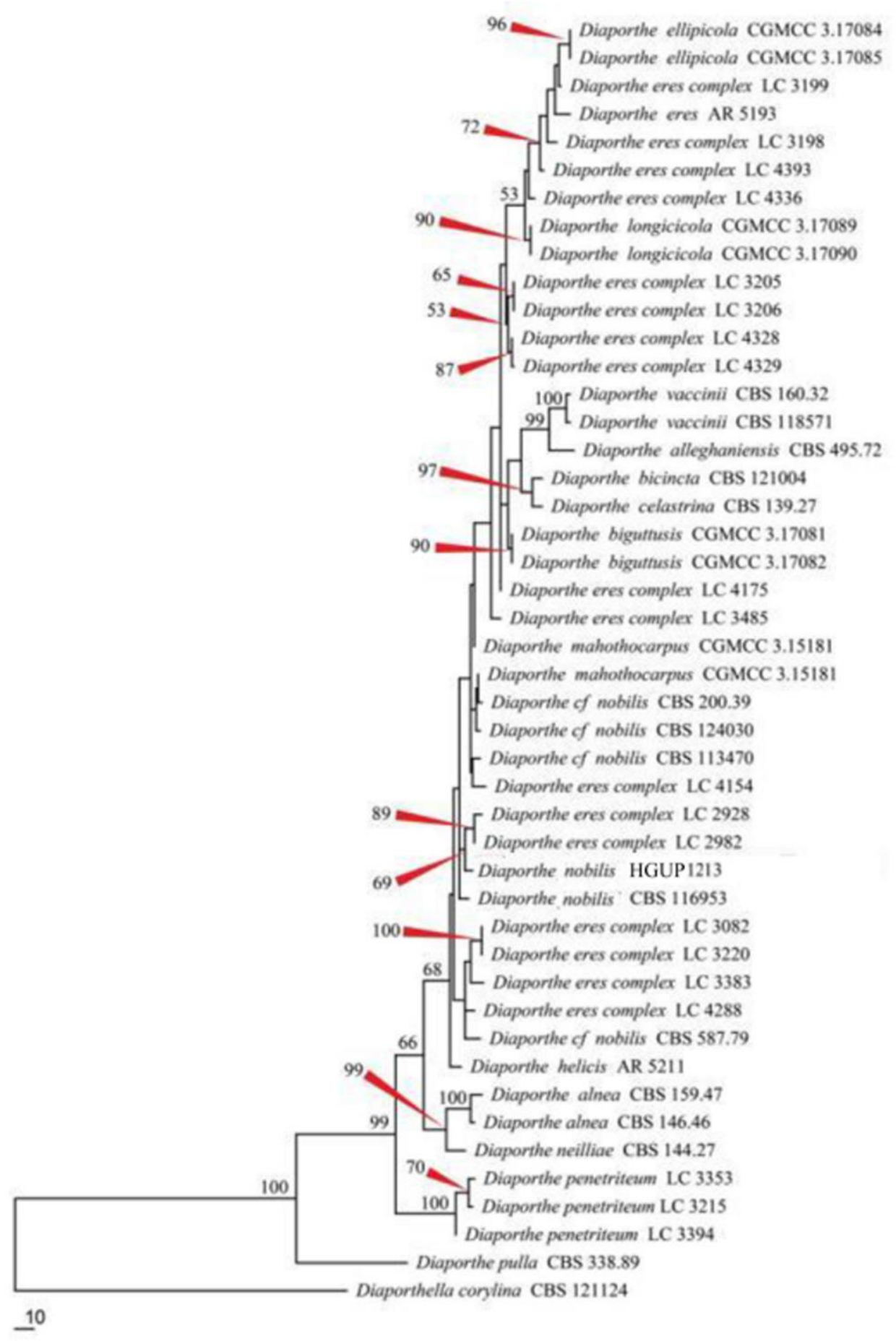

Fig. 1 - Topology showing the most parsimonious tree, inferred from combined ITS, beta-tubulin and tefl gene regions. Bootstrap values smaller than 50\% are not shown. The tree was rooted with Diaporthe citri (AR3405).

internal transcribed spacer (ITS), beta-tubulin and and tefl gene regions. Sequencing was performed with an ABI PRISM 3730 DNA autosequencer using either dRhodamine terminator or Big Dye Terminator (Applied Biosystems Inc., Foster 19 City, California). The sequences of both strands of each fragment determined for sequence confirmation. The DNA sequences of HGUP1213 in ITS, beta-tubulin and tefl regions generated in this study were submitted to GenBank (ITS: KC252992, beta-tubulin: KC252993 and tef1: KC252991). 


\section{Sequence alignment and phylogenetic analyses}

Sequences of our strain, along with references obtained from Udayanga et al. (2014), were aligned by Clustal X (Thompson et al. 1997). Alignments were optimized manually in Bioedit (Hall 1999). Phylogenetic and molecular evolutionary analyses were conducted using PAUP* (Swofford 2002) combined with ITS, $\beta$-tubulin and tefl dataset. Ambiguously aligned regions were excluded from all analyses. Unweighted parsimony (UP) analysis was performed. Trees were inferred using the heuristic search option with TBR branch swapping and 1000 random sequence additions. Maxtrees were 5000, branches of zero length were collapsed and all multiple parsimonious trees were saved. Clade stability was assessed in a bootstrap analysis with 1000 replicates, each with ten replicates of random stepwise addition of taxa (Felsenstein 1985).

\section{Results}

\section{Phylogenetic analysis}

In order to accurately identify our fungal isolate, ITS, beta-tubulin and and tefl sequences of 44 strains of Diaporthe species (mainly ex-type or epitype cultures) and important strains associated with Camellia (Gao et al. 2016) were aligned with our sequence data, for phylogenetic analysis. Sequences were obtained a 1324 aligned characters file. Among them, 180 characters were parsimony-informative. Diaporthella corylina (CBS 121124) was selected as outgroup following Gao et al. (2016).

The most parsimonious tree is used to represent the topology of the Diaporthe strains (Fig. 1), which indicated that all 45 isolates grouped as a single large clade with high bootstrap support (100\%). Tree length (TL) is 805 steps, consistency index (CI) is 0.73 , retention index (RI) is 0.78 rescaled consistency index (RC) is 0.57. In Fig. 1, HGUP1213 kept a closer relationship with CBS 116953 as D. nobilis, LC2982 and LC2928 as Diaporthe eres complex supported by a moderate bootstrap support (69\%), but relatively distant to other members of the D. eres species complex.

\section{Morphological description}

Diaporthe nobilis Sacc. \& Speg., Michelia 1 (4): 386 (1878)

Figs. 2-3

Facesoffungi number: FoF 02717

Habit leaves of Camellia sinensis. Substratum covered by a thin stromata of 3-4 layers of dark brown, thick-walled cells, epidermis evident below the stromata. Sexual morph: Undetermined. Asexual morph: Conidiomata are pycnidial, subcuticular, scattered to confluent, uniloculate, dark brown to black, uniloculate, broadly spherical to flattened, 650-700 $\mu \mathrm{m}$ high and 400-500 $\mu \mathrm{m}$ wide (Fig. 2f). Conidiomatal wall is dark-brown to black with textura angularis; ostiole is single, circular (Fig. 2g). Conidiophores thin walled, brown, vertically aligned, multicellular, cells 2-6 $\mu \mathrm{m}$ wide, elongate, tightly packed, textura prismatica, lining pycnidial base and sides up to apex (Fig. $2 \mathrm{~h}-\mathrm{j}$ ). Conidiogenous cells formed at the apex of the conidiophores, 8-18 $\times 0.5-1.2 \mu \mathrm{m}$, obclavate to cylindric, straight or curved, developing from the apex of columnar cells (Fig. $2 \mathrm{~h}-\mathrm{j}$ ). Alpha conidia $7-9 \times 3-5 \mu \mathrm{m}$ (av. $8 \times 3.8 \mu \mathrm{m}$ ), no septate, straight or curved, cylindrical or ellipsoidal, obtuse at the both ends, hyaline, generally biguttulate. Beta conidia 20-30 × 0.3-0.8 $\mu \mathrm{m}$ (av. $24 \times$ $0.5 \mu \mathrm{m}$ ), filiform, blunt at one end, pointed and usually curved at the other, hyaline, one-celled (Fig. $2 \mathrm{k}-\mathrm{n}$ ). Colony morphology: On $\mathrm{CZ} 3 \mathrm{~cm}$ diameter, dark brown to greyish orange at margin, surface mycelium appressed-felty, margin feathery, reverse dark brown to greyish orange at margin, 

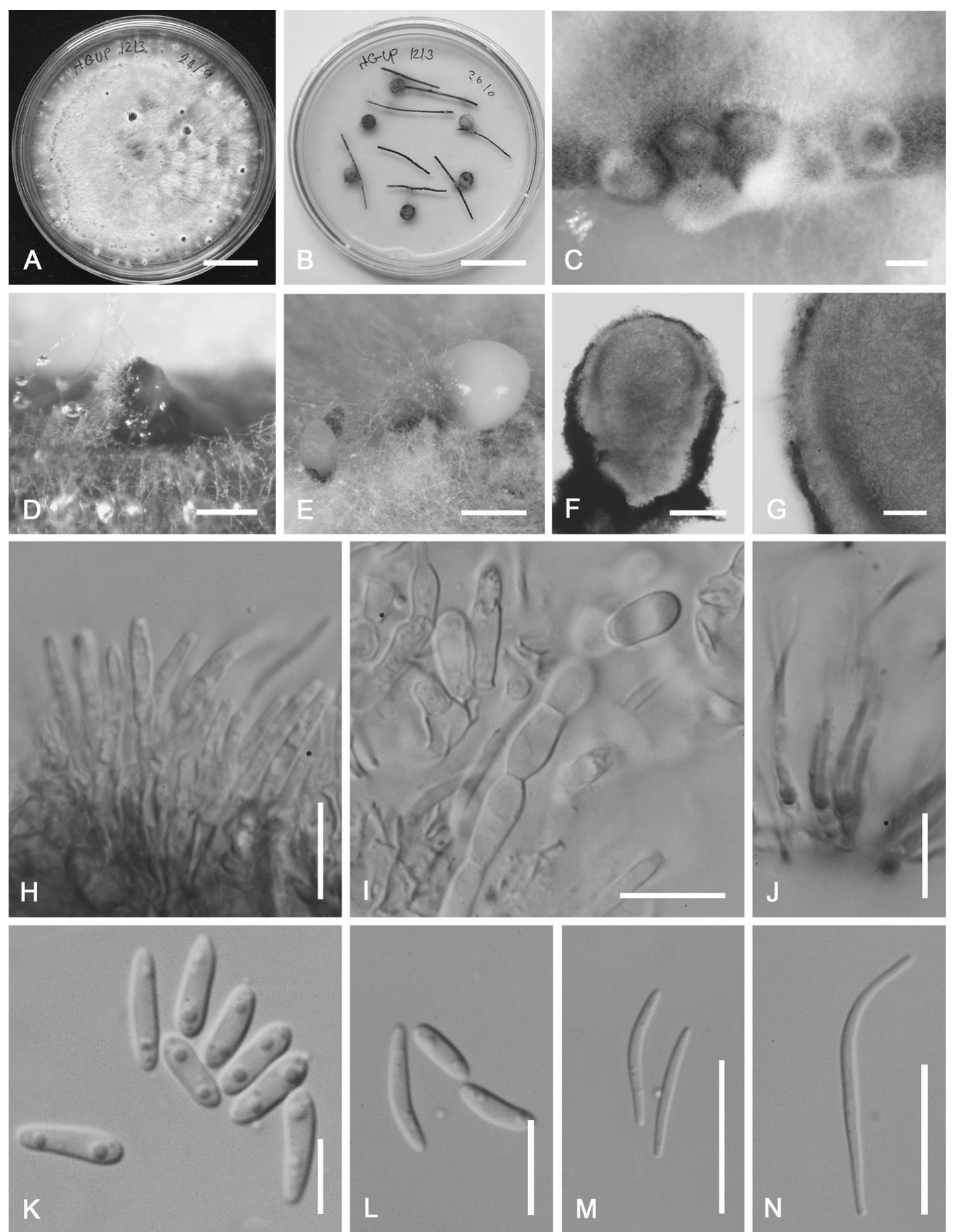

Fig. 2 -Diaporthe nobilis (HGUP 1213). a. Colony on PDA. b. Asexual morph on PDA with pine needles. c. Conidiomata. d-e. Pycnidia on PDA. f. Section of conidioma. g. Peridial wall. $\mathbf{h}-\mathbf{j}$. Conidiophores. $\mathbf{k}-\mathbf{n}$. Conidia. Scale bars: $\mathrm{a}, \mathrm{b}=2 \mathrm{~cm}$., $\mathrm{c}=500 \mu \mathrm{m}, \mathrm{d}=200 \mu \mathrm{m}, \mathrm{e}=500 \mu \mathrm{m}, \mathrm{f}=$ $200 \mu \mathrm{m}, \mathrm{g}=50 \mu \mathrm{m}, \mathrm{h}-\mathrm{j}=10 \mu \mathrm{m}, \mathrm{k}=5 \mu \mathrm{m}, 1-\mathrm{n}=10 \mu \mathrm{m}$.

without zones; on CMA $3 \mathrm{~cm}$ diameter, translucent, no surface mycelium, margin lobate, without zones; on PDA $6.3 \mathrm{~cm}$ after 7 days, white to olive grey surface mycelium cottony, radiate growth pattern, reverse black to dark brown, without zones (Fig. 3).

Material examined - CHINA, Guizhou Province, Huishui, on leaf spots on living leaves of Camellia sinensis, July 2011, P. Tan (GT11-4), living culture HGUP 1213. 


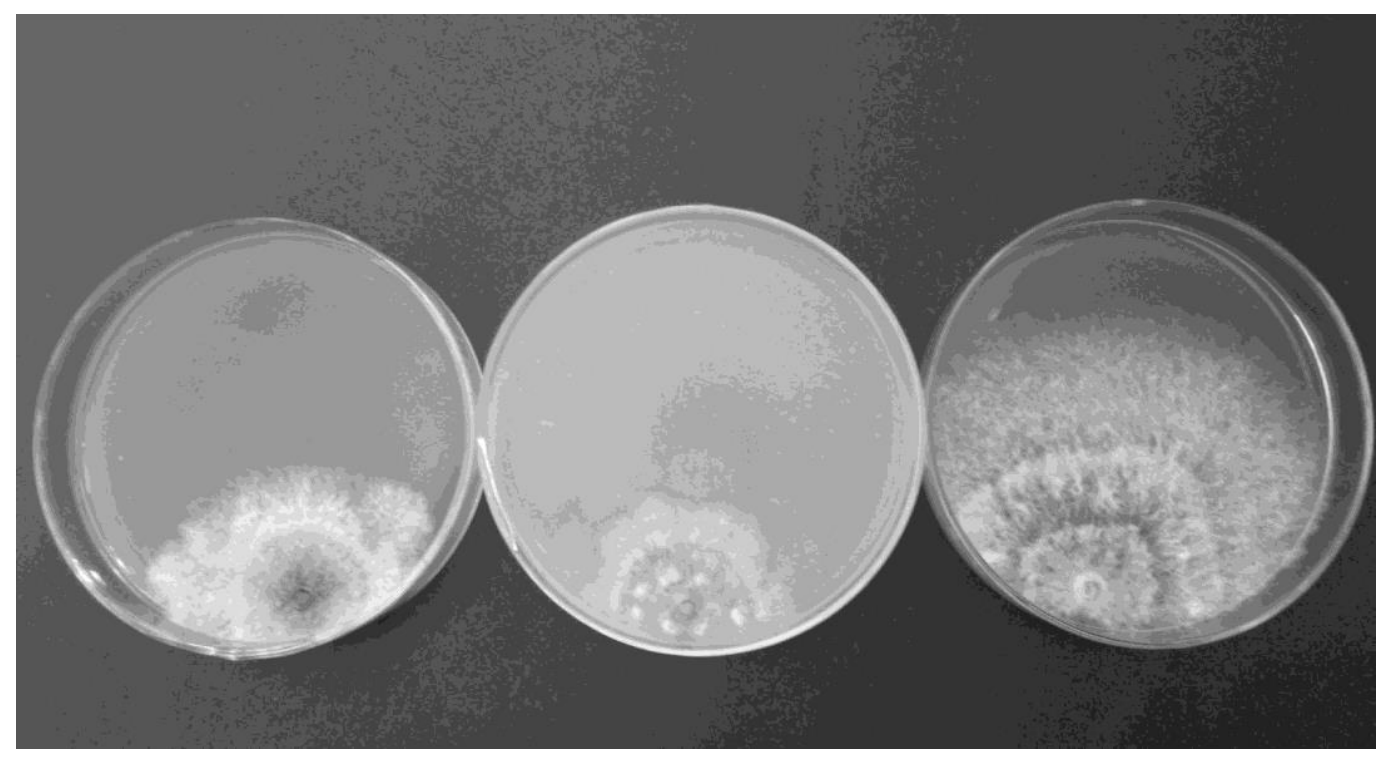

Fig. 3 - Diaporthe nobilis (HGUP1213) on CZ, CM and PDA media (from left to right).

\section{Discussion}

Placement of our Diaporthe species is suggested by a number of morphological observations as well as the molecular data analyses. It is placed in D. eres species complex by the phylogenetic tree based on three gene loci (ITS, beta-tubulin and and tef1), and then keeps a closer relationship with D. nobilis (CBS 116953) and two Diaporthe eres complex strains (LC2928 and LC2982) in Fig. 1. According to Udayanga et al. (2014), P. fukushii, D. castaneae-mollissimae and $D$. cotoneastri were synonyms of $D$. eres mainly based on multi-gene analyses. However, in this paper, we still looked them as different species for full morphological comparison. Beta conidia of our strain $(0.3-0.8 \mu \mathrm{m})$ were obviously narrower than those of D. eres $(1-1.5 \mu \mathrm{m})$. Between HGUP1213 and D. helicis, we could easily observe the beta conidia from HGUP1213, but $D$. helicis was not. Diaporthe cotoneastri produced fusiform $\alpha$-conidia, but $D$. theae-guizhouense produced smaller cylindrical or ellipsoidal $\alpha$-conidia (Abreo et al. 2012). Beta conidia of $D$. castaneae-mollissimae are straight or somewhat curved, but those of $D$. theae-guizhouense are hamate. D. castaneae-mollissimae was also reported by Chinese mycologists (Jiang \& Ma 2010) as P. castaneae-mollissimae and then combined by Udayanga et al. (2012) into Diaporthe genus. For D. vaccinii, its $\alpha$-conidia were bigger than those of our strain (Farr et al. 2002). Alpha conidia size of our strain were nearly identical to D. nobilis $(7.5-10 \times 2.5-4 \mu \mathrm{m})$. Phomopsis theae Petch could cause tea stem canker, which has been reported in Zhejiang and Anhui provinces of China (Jiang et al. 2006). In the beginning, we hypothesized our strain might belong to this tea pathogen. However, their ITS sequences were obviously different by NCBI-BLAST, but could not discover $P$. theae's beta-tubulin and tefl sequences. The phylogenetic results have determined that our strain was different to Diaporthe strains obtained from Camellia in China, except for LC2928 and LC2982. In Gao et al. (2016), they did not give a clear answer about their taxonomic placement but only as Diaporthe eres complex. Regretfully, not morphological description of these two isolates for taxonomic determination. Thus, combined the analyses of morphology and phylogeny, we described our strain, HGUP1213 as Diaporthe nobilis. This was also the first time to report it on Camellia sinensis. In view of the phylogenetic placements of LC2928 and LC2982, we thoughtfully proposed they was the same species with our strain. 
Although this strain was isolated from diseased leaves of Camellia sinensis, we re-inoculated by conidial suspension $\left(1 \times 105 \mathrm{~mL}^{-1}\right)$ and mycelium cake $(1 \mathrm{~cm} \mathrm{diam}$. $)$ to healthy tea leaves in three pots in my lab. However, the inoculation test confirmed it was not a pathogen but only an opportunity pathogen or endophyte. It was very common because Diaporthe spp. were important endophytes in many plant hosts. Thus, we did not provide any information about inoculation experiment and photographs of diseased leaves.

\section{Acknowledgments}

We would like to thank N. Wijayawardene for help with the morphological description of this species. This work was financed by grants from the Genetically Modified Organisms Breeding Major Projects of China [2016ZX08010-003-009], Agriculture Animal and Plant Breeding Projects of Guizhou Province [QNYZZ2013-009], National Science Funding of China (no. 31560489), Science and technology basic work of MOST [2014FY120100], and the grant [JD2014018] from Education Department of Guizhou Province.

\section{References}

Abreo E, MartÍnez S, Sessa L, Bettucci L, Lupo S. 2012 - Phomopsis cotoneastri as a pathogen associated with trunk cankers and death of young apple trees cv. Cripps Pink. Journal of Phytopathology 160, 434-436.

Carbone I, Kohn LM. 1999 - A method for designing primer sets for speciation studies in filamentous ascomycetes. Mycologia 91, 553-556.

Choi YW, Hyde KD, Ho W. 1999 - Single spore isolation of fungi. Fungal Diversity 3, 29-38.

Farr DF, Castlebury LA, Rossman AY. 2002 - Morphological and molecular characterization of Phomopsis vaccinii and additional isolates of Phomopsis from blueberry and cranberry in the eastern United States. Mycologia 94, 494-504.

Felsenstein J. 1985 - Confidence limits on phylogenies: an approach using the bootstrap. Evolution 39, 783-791. doi:10.2307/2408678.

Gao YH, Liu F, Cai L. 2016 - Unravelling Diaporthe species associated with Camellia. Systematic and Biodiversity 14, 102-117.

Glass NL, Donaldson GC. 1995 - Development of primer sets designed for use with the PCR to amplify conserved genes from filamentous ascomycetes. Applied and Environmental Microbiology 61, 1323-1330.

Guo LD, Hyde KD, Liew ECY. 2000 - Identification of endophytic fungi from Livistona chinensis (Palmae) using morphological and molecular techniques. New Phytologist 147, 617-630.

Hall TA. 1999 - BioEdit: a user-friendly biological sequence alignment editor and analysis program for Windows 95/98/NT. Nucleic Acids Symposium Series 41, 95-98.

Hawksworth DL. 2011 - Naming Aspergillus species: progress towards one name for each species. Medical Mycology 49, S70-S76.

Hyde KD, Hongsanan S, Jeewon R, et al. 2016 - Fungal diversity notes 367-490: taxonomic and phylogenetic contributions to fungal taxa. Fungal Diversity 80, 1-270.

Hyde KD, McKenzie EHC, KoKo TW. 2011 - Towards incorporating anamorphic fungi in a natural classification - checklist and notes for 2010. Mycosphere 2, 1-88.

Hyde KD, Nilsson RH, Alias SA, et al. 2014 - One stop shop: backbones trees for important phytopathogenic genera: I (2014). Fungal Diversity 67, 21-125. 
Jiang P, Wu MX, Han RJ. 2006 - Studies on occurrence and control of tea stem canker (Phomopsis theae Petch). Journal of Tea Science 26, 315-316.

Jiang SX, Ma HB. 2010 - A new species of Phomopsis on Castanea mollissima. Mycosystema 29, 467-471.

Li S, Wu X, Xue H, Gu B, Cheng H, Zeng J, Peng C, Ge Y, Chang J. 2011 - Quantifying carbon storage for tea plantations in China. Agriculture, Ecosystems and Environment 141, 390-398.

Liu JK, Hyde KD, Jones EBG, et al. 2015 - Fungal diversity notes 1-110: taxonomic and phylogenetic contributions to fungal species. Fungal Diversity 72, 1-197.

Nitschke T. 1870 - Pyrenomycetes Germanici 2: 245, Breslau. Eduard Trewendt, Germany.

Santos JM, Phillips AJL. 2009 - Resolving the complex of Diaporthe (Phomopsis) species occurring on Foeniculum vulgare in Portugal. Fungal Diversity 34, 111-125.

Shenoy BD, Jeewon R, Hyde KD. 2007 - Impact of DNA sequence-data on the taxonomy of anamorphic fungi. Fungal Diversity 26, 1-54.

Swofford DL. 2002 - PAUP*: phylogenetic analysis using parsimony (*and other methods), version 4.0b10. Sinauer Associates, Sunderland.

Thompson J, Gibson T, Plewniak F, Jeanmougin F, Higgins D. 1997 - The Clustal X windows interface: flexible strategies for multiple sequence alignment aided by quality analysis tools. Nucleic Acids Research 25, 4876-4882.

Udayanga D, Castlebury LA, Rossman AY, Chukeatirote E, Hyde KD. 2014 - Insights into the genus Diaporthe: phylogenetic species delimitation in the D. eres species complex. Fungal Diversity 67, 203-229.

Udayanga D, Liu X, Crous PW, McKenzie EHC, Chukeatirote E, Hyde KD. 2012 - A multi-locus phylogenetic evaluation of Diaporthe (Phomopsis). Fungal Diversity 56, 157-171.

Udayanga D, Liu X, McKenzie EHC, Chukeatirote E, Bahkali AHA, Hyde KD. 2011 - The genus Phomopsis: biology, applications, species concepts and names of common phytopathogens. Fungal Diversity 50, 189-225.

Wehmeyer LE 1933 - The genus Diaporthe Nitschke and its segregates. University of Michigan Press, Ann Arbor.

White TJ, Bruns T, Lee S, Taylor J. 1990 - Amplification and direct sequencing of fungal ribosomal RNA genes for phylogenetics. In: PCR Protocols: a guide to methods and applications (Innis MA, Gelfand DH, Sninsky JJ, White TJ, eds). Academic Press, San Diego, California, U.S.A., 315-322. 